\title{
The value of energetic analysis in architecture as an example for data sharing
}

\author{
Federico Buccellati ${ }^{\mathrm{a}, \mathrm{b}, *, 1}$, Eric Kansa ${ }^{\mathrm{c}, \mathrm{d}}$ \\ a IIMAS - International Institute for Mesopotamian Area Studies, United States \\ ${ }^{\mathrm{b}}$ Goethe University, Frankfurt am Main, Germany \\ c Open Context, United States \\ ${ }^{\mathrm{d}}$ Alexandria Archive Institute, United States
}

\section{A R T I C L E I N F O}

\section{Article history:}

Received 18 January 2016

Received in revised form

22 June 2016

Accepted 1 July 2016

Available online 2 July 2016

Keywords:

Chaîne Opératoire

Energetics

Kenan Tepe

Mozan

Open Context

Poggio Civitate

Urkesh

\begin{abstract}
A B S T R A C T
The process of construction of an ancient building can be broken down into a series of steps, and analysed using tools such as the chaine opératoire. This methodology permits one to explore the process, allowing for its disarticulation and a more complete understanding. It cannot, however, explore the temporal, material or energetic 'cost' of these steps. One can derive sets of cost-calculation-algorithms which can be applied to ancient architecture through 3D models which define the volumes of built material.

Such analyses can be applied to structures in any pre-industrial society, and, because of their nature, cross-cultural comparisons can be as meaningful as intra-cultural studies. Open-Context enables such studies by providing access to data needed for energetic analysis. Linking data in Open Context with costcalculation-algorithms allows greater reproducibility, while modular cost-calculation-algorithms enable the exploration of diverse choices. By making these cost-calculation algorithms open-source, we make parameters explicit, contestable, and reusable.
\end{abstract}

(c) 2016 Published by Elsevier Ltd.

\section{Introduction}

Architecture, as uncovered in the archaeological record, can be studied with the aim of understanding the energy needed for its construction. By understanding the steps of construction through a chaîne opératoire, one can break down the process of construction, defining and describing each step. Drawing on diverse sources, such as ethnographic materials, experimental archaeology, and ancient texts, we can build algorithms (computational models) to quantify the amount of energy needed in these steps. We can then visualize this with a 3D model that provides the precise volumetric dimensions of the constructed space (uncovered and reconstructed), differentiated by construction material. In this paper, we first discuss a study that used this approach to determine mudbrick production for the AP Palace at Tell Mozan, ancient Urkesh. To highlight the potential of this method, we then

\footnotetext{
* Corresponding author at: IIMAS - International Institute for Mesopotamian Area Studies, United States.

E-mail addresses: fab@urkesh.com (F. Buccellati), kansaeric@gmail.com (E. Kansa).

${ }^{1}$ Postal address: Vorderasiatisches Museum, Geschwister-Scholl-Straße 6, 10117 Berlin, Germany.

apply it to two other architectural datasets published in Open Context. Open Context datasets were ideal for this study because Open Context provides not only access to a wide range of datasets, but also an articulation to these datasets which allows for specific search parameters. Additionally, the use of persistent URIs for each element in the dataset allows other authors to cite these specific records, documents, and media items.

The methodology applied to the AP Palace can then be applied to other sites published in Open Context, such as Kenan Tepe or Poggio Civitate. The results not only aid in understanding the methodology, but also raise new questions.

\section{Energetics in architecture - a definition of method}

The study of architecture through energetics can be defined as the analysis of the construction of a building through the energy needed for the procurement, transportation, adaptation, and emplacement of the raw materials used in the construction (Abrams, 1994: 2). Thus, the energy can be calculated on the basis of work done (on an hourly basis) by one or more people involved in each of those steps. As a basic example, a stone foundation requires quarry workers who mine and finish stone, transportation to the 
construction site, and workers to cut the foundation trench and place the stone. At the basis of such an analysis three types of data are needed: a chaîne opératoire which attempts to define the steps taken, a set of 'algorithms' which define the hours needed for the tasks involved, and a quantification of the volumes of the ancient construction.

The chaîne opératoire is a method of analysis which focuses on the individual steps taken during the production of an object; the method was initially developed for lithic analysis, but it has been adapted here to describe the steps taken in the construction of architecture. The chaîne opératoire unpacks a generic 'moment of construction' into a series of discrete steps, including the procurement of all of the raw materials needed, their use in the manufacture of building elements, the transportation involved as well as their placement in the structure itself. While no numeric values are generated, a series of questions regarding such a construction arise: where is the nearest source of stone? Could streams have been used in the transportation of materials? And what effect might the workspace needed for mudbrick construction have had on local agriculture? Such questions help clarify the practical dimension of the construction process, and can aid in the definition of the choices made in the design of a particular building. Furthermore, the chaîne opératoire helps formulate a timeline for the construction process: mudbricks could only be made in certain periods of the year, for example.

The chaîne opératoire method as applied in this paper focuses exclusively on the technical aspects of construction rather than additionally exploring the social framework (or 'total social phenomenon' in Mauss' terms) in which this process develops. In fact, definitions of the chaîne opératoire vary (Martinón-Torres, 2002) from the narrowest technical "Leroi-Gourhan defined this as the series of technological operations which transforms a raw material into a usable product" (Cresswell, 1990: 46) to the widest cognitive "integrated webs weaving skill, knowledge, dexterity, values, functional needs and goals, attitudes, traditions, power relations, material constraints, and end-products together with the agency, artifice, and social relations of technicians" (Dobres, 1999: 128). While it is true that a technical analysis tends to exclude the social aspects, at least initially, the case can also be made that only after a detailed understanding of the technical side can even some of the social questions be considered.

The study of energetics of construction also requires modelling theb 'algorithms' of construction. These aim to quantify one or more variables in a specific activity. This variable can be materials used in the process, materials produced in the process, workforce needed and/or the time needed to complete a task. The sources for these algorithms can be placed in three categories: ethnographic observation, experimental archaeology, and textual sources.

Ethnographic observations include research done by scholars (primarily anthropologists) looking at modern work situations. These observations establish a relationship between the variables being considered (materials used, end product, workforce required and the time needed for tasks) that are common to the culture in which they are working, and come from a wide range of geographic regions and chronological periods. It should be noted that what is being drawn from these studies is not related to actor intentionality as would be the case with a thick description (Geertz, 1973: 13-16), but rather the sequence of operations being performed as described in the 'unpacking' of the chaîne opératoire, and variables relating to those operations. These are clearly influenced by a large number of factors including those relating to the actors involved, but intentionality does not play a role when considering the technical aspects of the chaîne opératoire, as we do here.

The second category of sources, those deriving from experimental archaeology, is similar to ethnographic observations but for one aspect: the process being studied is not part of the activities normally carried out, but rather attempts to re-create elements of material culture found in the archaeological record. The distinction is important, as the data derived from experimental archaeology is based on the archaeologist's re-creation of an otherwise undocumented process. This re-creation is normally derived from information obtained from local informants (who may know and work with the materials already) as well as research done by other scholars.

The third group of algorithms comes from textual sources. These are normally ancient administrative texts which describe specific processes. From these texts we can derive algorithms that include the variables under consideration for a specific process: materials used, end product, workforce required and time needed.

The specific algorithms derived from these three sources form a guide which can be used in the study of energetics rather than a set of fixed rules, since the conditions, materials, skills, working conditions, psychological considerations and physical characteristics of the workforce all influence the variables under consideration. Ideally, the same algorithm would be derived from all three sources, as a way to understand the impact of these secondary influences; however, the ancient situation may have been impacted by these influences in ways which are incalculable today. A consideration of the use of these sources to generate algorithms, and their validity as applied to the archaeological record, is beyond the scope of this paper, but has been treated elsewhere (Buccellati, forthcoming).

The third and last type of data when considering the energetics of construction is a quantification of the constructed volume in the archaeological record, in order to apply the algorithms to a specific edifice. 3D models are becoming more and more ubiquitous in archaeological projects, and the perform a wide variety of functions, from communication to planning of future excavation areas (see Buccellati (2015) for further discussion of 3D models and their use in archaeological fieldwork). One oft-overlooked (in archaeology) function of 3D modelling software is the ability to calculate, with great precision, the volume of the individual blocks used in the model. This is fundamental for the analysis of energetics, as the quantity of specific construction elements can be queried from such a model, and the algorithms described above can be applied to a specific edifice. It is important, however, that the 3D model be a model of the archaeological record, and not a possible reconstruction of the building. It is also important that the model differentiate, using solid blocks, between the diverse materials used in the construction, so as to derive the volumes of specific materials used.

Thus the chaîne opératoire provides an understanding of the process of construction in its diverse facets; the algorithms provide a general guide to calculating the materials used, end product, workforce required, and time needed for the various tasks; and the 3D model provides the specific volumes of constructed space which are the input needed in the algorithms to estimate the 'cost' in terms of time, workforce and materials of a specific building.

An in depth study of this method as well as the results of its application to the AP Palace at Tell Mozan, ancient Urkesh are to be published in a forthcoming monograph entitled Three-Dimensional Volumetric Analysis in an Archaeological Context: The Palace of Tupkish at Urkesh and its Representation (Buccellati, forthcoming). This royal palace, built in the latter half of the third millennium BC during the Akkadian Period, is a prime example of monumental architecture. The aim of this paper is to show how comparative data from Open Context can aid the research goals through the availability of comparative material and potential for larger scale comparative analyses. 


\section{The AP palace at ancient Urkesh}

The AP Palace at ancient Urkesh provides an example of this method; while the palace as a whole is described in the monograph mentioned above, one example will aid the reader in better understanding the method presented here. Mudbrick, the most ubiquitous building material in Mesopotamia, is used as the primary building material in the AP Palace.

The chaîne opératoire for mudbrick manufacture is shown in Illustration 1; this is a reconstruction of the process used at ancient Urkesh, but would be the same throughout the ancient Near East.

The components needed are clean dirt, water and straw, which are mixed and used to fill a brick form. The brick is left to dry, and needs to be turned on its side at a certain point in the drying process. It is then ready to be used, transported and/or stored. Each of these steps (construction, transportation, storage) can be analysed in a further chaîne opératoire, and can lead in turn to further processes which can be likewise studied.

During an ethno-archaeological study done at Mozan, several thousand mudbricks were made with the same dimensions as ancient bricks. While modern houses in the local communities also employ mudbricks, the dimensions differ from those which are 'standard' in ancient Mesopotamia around the time of the construction of the AP Palace; thus although the brick size changed, much of the technique was already known to local builders. In the study,

4 people over $12 \mathrm{~h}$ (in 3 days).

produced 1000 mudbricks $(40 \times 40 \times 12 \mathrm{~cm}$ in size $)$ totalling $19.2 \mathrm{~m}^{3}$.

Thus approximately 2.5 man-hours are needed to produce one $\mathrm{m}^{3}$ of mudbrick.

Finally, the 3D model of the AP Palace gave a total volume for the mudbrick wall portions found in the archaeological record. The total volume of the mudbrick walls in the archaeological record is $223.22 \mathrm{~m}^{3}$; taking a standard height for all the walls, the total (minimum) reconstructed wall volume is $991.38 \mathrm{~m}^{3}$. After having removed $1 / 6$ of the volume for mortar (derived from another algorithm), the total volume of the mudbricks used in the construction is $826.15 \mathrm{~m}^{3}$, which is the volume of 51,634 bricks of the $40 \times 40 \times 12 \mathrm{~cm}$ size.

Putting these pieces together gives a total of 2065 man-hours needed to produce the necessary bricks, or 258 8-h working days.
Note that this is merely the time needed to produce the bricks themselves: additional time would have been needed to collect the requisite straw, dirt and water, as well as transport the bricks to the construction site for use in the actual building.

This kind of precise data about the construction process enables a whole set of comparisons between buildings on the same site or in other settlements, and allows for discussions on monumentality or prestige to be based directly on archaeological data. At this point, one might ask: after developing a method and applying it to a case study, what is the next step? Answering this question requires looking more broadly at changes in archaeological practice. Just as archaeology has increasingly embraced new media for visualization and computational modelling techniques such as the construction logistics algorithms described above, digital data in archaeology has assumed greater importance. To enable broader comparative study of the results from Tell Mozan, we need effective strategies to preserve data and to make these data discoverable and reusable. The following section introduces some key aspects of the emerging world of "open data" in archaeology.

\section{Beyond a single case study: the role of open data}

As computational methods gain traction, archaeologists must navigate complex challenges in research data management, especially with regard to the dissemination and preservation of software code and data. As discussed below, professional incentives, marketing strategies by established journals, political and ethical debates about open access, and the special demands and affordances of digital media all make scholarly communications in this area especially contentious.

In the United States, the European Union and elsewhere, government agencies funding research have started to develop and enact policies to encourage researchers to share their data. Following the pioneering efforts of the Archaeology Data Service, several digital repositories have emerged (Digital Antiquity's tDAR repository, and the German Archaeological Institute's IANUS repository) to help archaeologists share and preserve datasets. In response to the growing public policy debates about the costs of academic publishing and open access alternatives (see Lake (2012) and Kansa (2012)), most such repositories have relatively liberal access and intellectual property licensing conditions, especially

\section{Chaîne opératoire: Mudbrick Production}

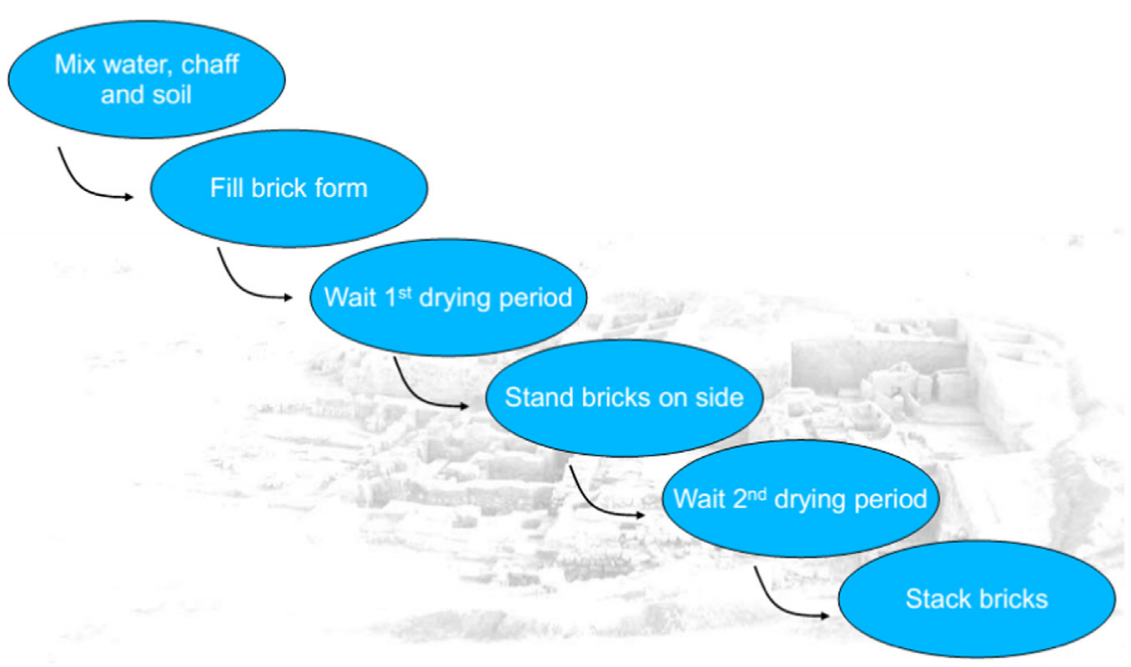

Illustration 1. Chaîne opératoire describing mudbrick production in the ancient Near East. 
when compared with mainstream journal publishers. Simply stated, much of the value of digital data (and code) centres on the potential to reuse, modify, and recombine content obtained from multiple sources. Unfortunately, the legal default of copyright expressly prohibits these forms of reuse without express permissions from the copyright holder. Because of the complexities of copyright law, including the threat of severe civil and criminal punishments (for archaeology see Kansa et al. (2013)), relaxed intellectual property (IP) conditions represent a fundamental aspect of "best practice" in promoting data interoperability and transparency and replicability of software code and computational modelling. Because of these licensing needs and the need for special digital preservation processes, many journals (including this title) now specifically recommend that authors submit datasets relating to a paper to a digital repository.

The growing use of digital repositories in mainstream academic publishing represents a welcome development in promoting data preservation. However, as shown in this paper, scholarly communications need to go far beyond the preservation of bits of data. While necessary, repository deposit alone is not sufficient to fully recognize or encourage intellectual investment in data and code. For data and code to be valued and used in scholarly discourse, they need to be more than afterthoughts of "supplementary materials" that may (at best) see repository preservation. Instead, data and code need dedicated dissemination channels better suited to the affordances of digital media. Key needs for the scholarly dissemination of digital data and code include:

(1) Inspection: Computer models and simulations have certain advantages over purely narrative approaches in archaeological interpretation and modelling. To a greater degree, computational models require a greater degree of formalism and specificity about how different modelling parameters are used. With access to the "source code" of such models, researchers would be able to independently review and refine models and better critique modelling assumptions. Rather than simply making a neat final product available, version control systems make the development and revision history, including comments and debugging efforts visible for review.

(2) Iteration: Making modelling source code publicly available also enables more rapid and wider collaboration around developing and refining models. Public version control systems, such as GitHub, make it easier for wider communities of researcher to develop models, identify problems, and test different modelling parameters. Technologies to support social collaboration (issue tracking, comment features, and user management) become important elements in the effective dissemination of research software and models.

(3) Re-purposing: Open intellectual property licensing together with public version control in systems like GitHub make it possible to "fork" (duplicate and modify) source code for new applications. The owners of the original code can maintain or develop their code as they see fit, but through forking, others can adapt a body of code to meet new purposes and needs.

Though the three points above focus mainly on software, capabilities for inspection, iteration, and repurposing are also important in research data management. Indeed, much of the media that archaeologists consider to be "data" have a great deal in common with software source code. For example, the rows and columns in a relational database table or spreadsheet are usually encoded as structured text, commonly CSV files. Computer source code is also a form of structured text that must adhere to certain syntax rules and semantics to execute. Thus, popular software version control systems can and do see use for data, including documenting version histories, tracking issues, "forking" and other forms of dissemination. Open Context, the data publishing platform discussed in this paper, uses GitHub for public version control of datasets so as to explicitly and precisely document changes (edits, error corrections) made on published data. While Open Context is the single largest provider of archaeological data on GitHub, several other archaeologists and projects use the same platform for version control.

Public version control systems emphasise iterative and public processes of knowledge creation (as expressed in code, and also data) and curation. Thus, the research process as a whole can be reviewed and evaluated by a wider community rather than only neatly packaged final research products like books and articles. This highlights how computational approaches in archaeology impact scholarly practice in profound ways. Not only does computation offer new methods to investigate the economics of monumental architecture with much greater precision and formalism, computational methods also raise important questions about dissemination and publication. The research process as a whole can be much more richly and explicitly documented with version control systems.

This study's reuse of data from the Kenan Tepe project (see below) helps to illustrate some of the research value of more widely exposing the research process. Open Context published primary documentation of Parker and Cobb (2012) and colleagues excavations at Kenan Tepe in 2012. The Kenan Tepe dataset published by Open Context includes excavation diaries, rich context descriptions (as structured data), artefact descriptions, as well as zooarchaeological and other specialist datasets. Over 30,000 excavation plans, field photos and artifact photos link directly to records of contexts and finds.

The size and complexity of the Kenan Tepe dataset in Open Context illustrates some of the challenges in making data accessible, discoverable and intelligible to a wider research community. Much of the data and metadata for the Kenan Tepe dataset came from several relational databases, spreadsheets, and even the directory structure and file names of the images. In a conventional digital repository such as the ADS or tDAR, these different files would be archived with metadata, ideally including detailed descriptions of the database structures and entity relationships.

However, the scale and complexity of Kenan Tepe would make difficult to use Kenan Tepe's data if it was stored in a conventional digital repository. One would have to download and rebuilt the relational database and use available metadata documentation to understand how to query it, even before one could begin exploratory searches. More over, because information from the Kenan Tepe project came from multiple files, one would have to download and look in multiple files for relevant information. Thus while digital repositories play an essential and necessary role in preserving our discipline's digital data, archaeology still needs to better strategies to make these kinds of data discoverable and usable.

Open Context explores some of these access and reuse questions to make data preserved in repositories more usable. Rather than storing data files as objects of preservation, Open Context publishes data in much smaller and more granular level. Open Context publishes a small Web resource (identified by a stable Web URI) for each archaeological "entity" defined by source databases, spreadsheets, and the like. Each bone, potsherd, context, coin, etc., gets its own Web page and machine-readable data equivalent (in the JSON-LD format). While Open Context retains the descriptive properties and terminologies used by the contributors, Open Context editors also use common controlled vocabularies and ontologies to further annotate these records to facilitate cross-project searching and indexing.

Open Context's "data sharing as publishing" approach facilitated comparative analysis with Tell Mozan architecture. The 

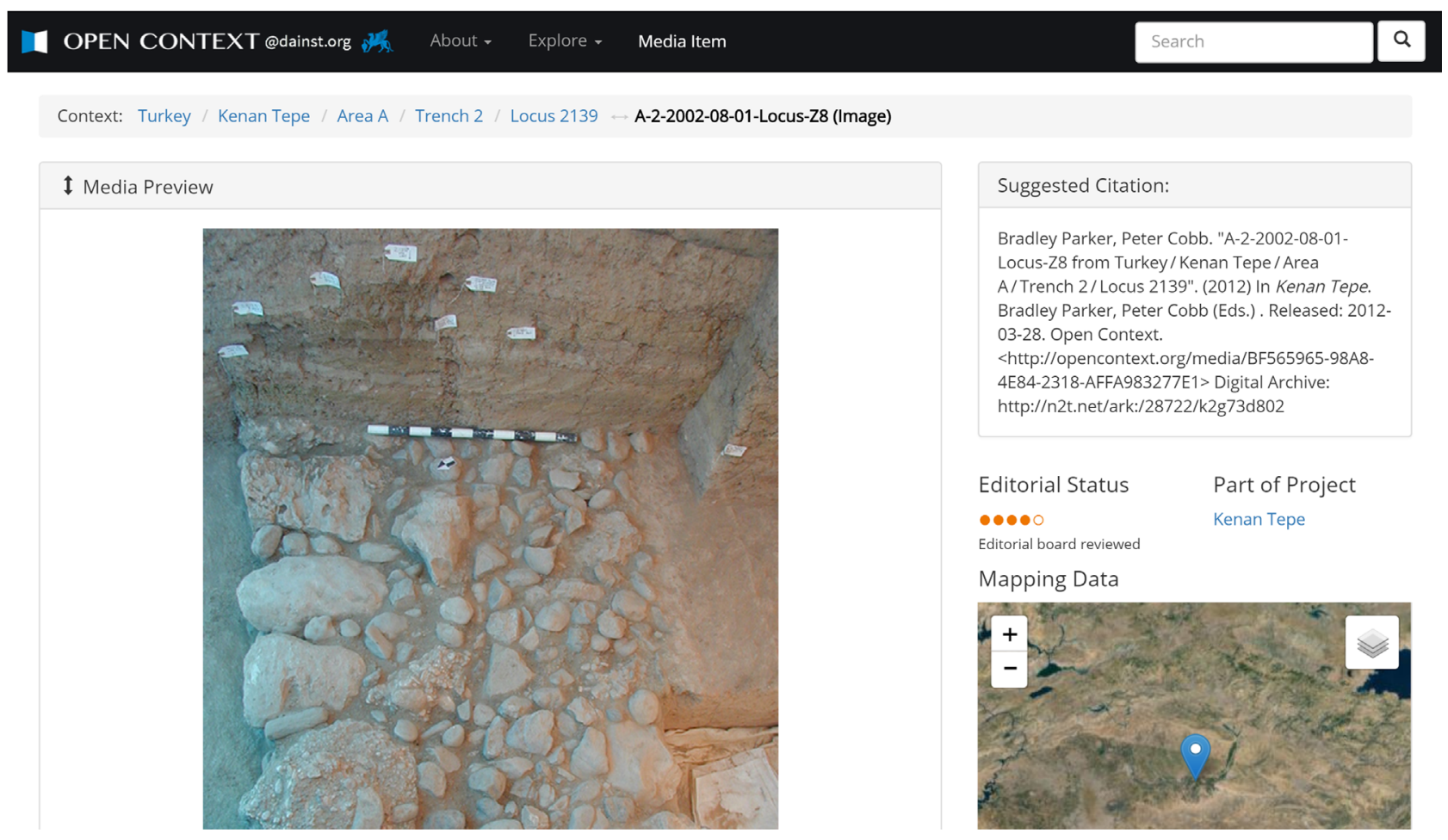

Illustration 2. Image of Open Context entry from the Kenan Tepe Project showing locus 2139 which contains a portion of the LC Settlement wall.

Kenan Tepe project dataset published by Open Context contained context records, excavation logs, photos, and excavation plans that documented a Late Chalcolithic era fortification wall. These records contained excavation notes and images from which one could obtain (or infer from photographic evidence) the measurements of stone foundations, mudbricks, and preserved wall heights (See Illustration 2).

Dynamic access to "live" data (rather than only metadata description of files) enabled easier exploratory search and browsing to find the relevant records. In addition, because each of these records has its own stable Web URI (and digital library archival identifier), one can cite the specific source of information used to modelling Kenan Tepe's Chalcolithic wall. Instead of citing a data file that may contain thousands of excavation records, this more granular approach to data citation promotes more clear documentation of specific sources - an essential element of more reproducible research.

While granular citation, indexing and dynamic access to data all facilitated comparative analysis of Tell Mozan and Kenan Tepe, the usability of data published by Open Context also benefited from other, more conventional forms of publication. It would have been very difficult to use the Kenan Tepe dataset by itself without reference to the many field reports and synthetic publications available about the site. Without these publications, it would be difficult to wade through the masses of "raw" excavation data and notes to understand significance, and the larger picture of how the smaller pieces of primary excavation documentation relate together into a coherent whole. The Kenan Tepe dataset published by Open Context includes a rich bibliography that documents publications interpreting different excavation areas and Trenches. Through reference to these publications, it was possible to "know what to look for" and conduct more targeted searches for specific details about the Late Chalcolithic wall.

This point highlights how we need to consider questions of data sharing and reuse in the larger context of scholarly communications. Different modes and models of scholarly communication can serve different and complementary roles in facilitating research. Data dissemination and more familiar forms of conventional academic publishing need to articulate well with one another to enable the kinds of research outcomes presented in this paper.

Digital data (and code) are not merely issues of long term preservation. While preservation is a vitally important issue, the "datafication" of archaeology involves much more fundamental challenges to existing practices in collaboration and publication. Better communication of the research process, as revealed through well documented and curated data and well documented and version controlled software will be increasingly important. Moreover, data reuse represents many challenges. Kenan Tepe's vast and complex dataset would be very difficult to use if it was only archived in a repository and not dynamically accessible with Open Context. However, Open Context's approach to data publication and hosting is more expensive and more difficult to scale that conventional repositories. This issue highlights how we need a great deal more experimentation and wider scholarly engagement with cost effective ways to make data more widely (re)usable for the kinds of applications presented in this paper.

\section{From the Kenan Tepe dataset to the algorithms}

Thus data presented in Open Context opens new opportunities for applying and improving modelling techniques as developed for the case study of the AP Palace at Mozan. Without systems like Open Context, it would be very time consuming and difficult to obtain the excavation records and field notes needed to obtain the specific volumetric data to use with the algorithms. These details are often omitted from a conventional final publication. More comprehensive forms of digital publication, such as those developed by Open Context, are needed to make the detailed record of field work available and usable for this form of comparative research. To gather the requisite data for further studies using the proposed method, in the past, one would have to open another excavation area at the same site or go to another excavation to 
Table 1

Data from the Kenan Tepe dataset, along with stable URIs.

\begin{tabular}{|c|c|}
\hline Information & Stable URI \\
\hline $300 \mathrm{~m}$ wall circumference (estimated based on geomagnetic sounding, approximate) & http://arcserver.usc.edu/reports/reports/TAA_2000_to_2007.pdf \\
\hline Wall foundation about $1.8 \mathrm{~m}$ thick & http://opencontext.org/media/BF565965-98A8-4E84-2318-AFFA983277E1 \\
\hline Brick dimensions: $34 \times 31 \times 9 \mathrm{~cm}$ & http://opencontext.org/subjects/975143F2-B80E-436B-B078-1D67FD848352 \\
\hline Surviving wall height: $1.2 \mathrm{~m}$ & http://opencontext.org/subjects/02B9D6E6-D6AD-4138-7FCC-3EF6F8BD5722 \\
\hline
\end{tabular}

undertake new fieldwork and data collection - 'ground-truthing' in the sense that one had to go and excavate or document the example being used in the study. The advent of Open Context changed this pattern: it provides not only the data needed for such a ground-truthing, but comes with the tools to find a dataset with the required data within a region or time period.

The site of Kenan Tepe, situated in modern Turkey, is one of the best sites in Open Context to compare with Tell Mozan due to its vicinity in space and time, the similarity of construction material and the quality of the documentation. By searching Open Context's records of Kenan Tepe for the keywords "mudbrick" with "size", five records are given. According to one of these records, the brick size used in the Late Chalcolithic settlement's defensive wall is given as $34 \times 31 \times 9 \mathrm{~cm}$; this information can be found here: http://open context.org/subjects/975143F2-B80E-436B-B078-1D67FD848352.

The ability to point directly at the specific data being referred to as a stable URI is one of the strengths of Open Context, and provides the kind of reference structure needed when publishing such a 'ground-truthing'. Further information needed to apply the algorithm can be found in the dataset:(Table 1).

Looking at this data, one can determine that the Late Chalcolithic settlement wall at Kenan Tepe was $300 \mathrm{~m}$ long, $1.8 \mathrm{~m}$ wide and is preserved to a height of $1.2 \mathrm{~m}$. That gives us a volume of $648 \mathrm{~m}^{3}$. Removing $1 / 6$ for mortar, we are left with $540 \mathrm{~m}^{3}$ of mudbrick. Estimating an original height of $2.5 \mathrm{~m}$ (a conservative estimate), the volume would have been: $1350 \mathrm{~m}^{3}$, or $1125 \mathrm{~m}^{3}$ of mudbrick without mortar.

Going back to the algorithm given above for mudbrick production, this means that $540 \mathrm{~m}^{3}$ of mudbrick would have needed 1620 man-hours to produce, while the $1125 \mathrm{~m}^{3}$ would have needed 2812 man-hours.

This is just one example of how the algorithms developed for the AP Palace at Tell Mozan can be applied to other datasets. Such an application can have many results: a ground-truthing of the method itself, a better understanding of the material culture at a second site, and/or a second construction which can be used in a comparative analysis in conjunction with the original case study.

Applying algorithms to these two datasets has given results in terms of man-hours of work for production. Clearly, the point of departure is different though - it will not have escaped notice that one dataset describes a royal palace while the other describes a defensive wall around a settlement. When a mudbrick royal palace becomes available as a dataset a follow-up study to this one will be a priority; however, the comparison between a palace and a settlement wall is fruitful as well.

Consider Trigger's thoughts on energy and architecture: "At the most elementary and general level, political power is universally perceived as the ability to control energy. No ruler can retain political power if he does not invest much of this energy in activities that help to maintain and, if possible, to expand the society that he controls. Yet the most compelling demonstration of power is the ability of a ruler to consume some of the energy he controls for non-utilitarian purposes" (Trigger, 1990: 125). The comparison between the energy needed to produce the bricks for a Royal Palace and the energy needed to produce the bricks for a settlement wall can be seen as a study into the difference between the utilitarian and non-utilitarian energy consumption in construction projects. Kenan Tepe is a smaller, older site, with a settlement wall measuring $300 \mathrm{~m}$; ancient Urkesh, at the time of the construction of the AP Palace had a settlement wall measuring approximately $4000 \mathrm{~m}$. The man-hours needed to make the bricks for the Kenan Tepe settlement wall was 2812, while the man-hours needed for the bricks used in the AP Palace construction was 2065.

The fact that a settlement wall for a small settlement dating to the fourth millennium would require more energy to construct than the monumental palace of a king who ruled over an important city-state of the middle third millennium may be surprising. The difference between the two lies in the necessity: the settlement wall, which would have been constructed when the need arose and thus, in the words of Trigger, 'necessary for the maintenance of the society' (even if probably not commissioned by a ruler in this case), can be set in contrast to the AP Palace, which would have corresponded to the 'non-utilitarian purposes' in Trigger's formulation.

Clearly, the AP Palace was made of a wide range of construction materials, which included stone, wood and gypsum plaster, to name a few, and the number given is only for the excavated portion of the palace; the settlement wall of Kenan Tepe, on the other hand, was primarily made of mudbrick. Thus the comparison in terms of total energy needed for the two projects (accounting for all construction materials) would show that the AP Palace was more costly (in terms of energy). However since mudbricks were the most common construction element in the AP Palace, the comparison based on mudbricks made above is still quite telling.

Such a comparison is by no means an argument which provides a conclusion; much more, it is a comparison which leads, heuristically, to a question which might not have been posed. Can the surplus or non-utilitarian use of energy in a society be put in direct relation to other 'necessary' projects that the same society undertook?

\section{Outlook: Poggio Civitate and algorithm version control}

The Kenan Tepe example above showed a comparison between a mudbrick defensive wall and a palace construction at a site within the same broad cultural context. The level of detail offered by the data published in Open Context allows scholars to cast a wider net when seeking comparative material. Another dataset (from among the 57 projects represented at the moment in Open Context) of interest in the context of this paper is that of Poggio Civitate (Tuck, 2012).

Poggio Civitate is an Etruscan settlement located in central Italy. The project in Open Context contains datasets, images, and field diary entries from fifty years of excavation at the site, including the documentation of several monumental buildings. Though Poggio Civitate is quite removed from ancient Urkesh in time and space, the use of stone in monumental construction projects is a common element between the two sites (see, for an example of a building at Poggio Civitate here: http://opencontext. org/media/0630a396-8886-4bdc-8754-c6d9600cb11b), and the temporal and spatial distances may serve to focus on 
commonalities between the two construction projects when discussing over-arching themes such as monumentality and prestige.

An in-depth comparison between the AP Palace and the structures uncovered at Poggio Civitate would give another example of how the datasets present in Open Context can be used in concomitance with new data and/or methodologies to enhance their value and broaden their scope.

As discussed above, data dissemination methods can help widen the scope for future comparative studies of the energetics of monumental architecture. At the same time, advances in scholarly communications can widen the applicability and improve the reproducibility of the algorithms used to model monumental construction activities. For example, public version control systems such as GitHub, if properly archived by nonprofit digital libraries and archives, can play an important role in the publication of software that encodes the algorithms used in studies like this. Full disclosure of the code will enable other researchers to understand, evaluate, "debug" and improve upon models. However, effective dissemination of modelling code is not just a matter of version control and archiving. The research community also needs to develop review processes and needs to cultivate appropriate rewards and incentives to share code. Open Context and other "data journals" (such as the Journal of Open Archaeological Data, and Internet Archaeology) work to improve research data usability and professional recognition. Similarly, the archaeological research community needs professional venues dedicated to the publication of modelling code. The current absence of professional venues to publish modelling code in archaeology represents key obstacle in promoting rigor and reproducibility of computational approaches to archaeology.

\section{Conclusions}

This paper has introduced computational methods to explore the energetics involved in the construction of ancient monumental architecture. The modelling algorithms introduced in this paper provide more explicit ways to understand labour investment and organization in ancient societies. The question was then raised: how does one go beyond the initial case study? This paper explored how these modelling algorithms could be used in comparative studies, providing a rich field for 'ground-truthing' such models. To enable such analysis, this paper highlighted the central importance of richly detailed, accessible and easily referenced comparative excavation data. This study, and others like it, also contribute to the information design for data collection and digitization programs by showing how the data is being accessed to answer specific queries. Specifically, the types of information searched for when exploring the Kenan Tepe archive is contributing to the ongoing digitization of the Poggio Civitate material, which includes 50 years of pre-digital excavation journals, photos, and plans alongside more recently structured data.

Thus, this paper highlights how access to richly documented and detailed primary data works in synergy with new computational modelling approaches, enabling an applicability to a wide range of archaeological contexts otherwise impossible. As data archiving and dissemination become more expected and professionally recognized research outcomes, the potential to further develop methodologies based on computational modelling will grow. The increasing interpretive significance of data and code will parallel established forms of scholarly communication, enhancing not only the number and scope of the examples from which it draws, as is the case in this paper, but also allowing for a wider dissemination of both data and interpretation.

Furthermore, just as Open Context has helped to pioneer approaches to "data sharing as publication" in archaeology (exemplified above in the examples from Kenan Tepe and Poggio Civitate), our discipline similarly needs venues to promote professional communication of software and modelling code - the algorithms discussed in this paper. In illustrating how data and code can work together to enrich our understanding of the past, this paper highlights the key role of scholarly communications systems in computational methods - as these methods become useful as tools applicable to a wide range of contexts, communication must adapt to disseminate these tools in a way that allows for their full integration into a wide range of scholarly projects. The digital revolution in archaeology is far from complete. While our discipline has just begun to widely recognize the vital importance of data preservation, sharing and reuse, few have considered the growing importance of software and modelling code. Therefore we call on the archaeological community to widen its horizons and promote professionalism and recognition for contributions of code as well as data.

\section{Acknowledgements}

Thanks goes to the Mozan/Urkesh Archaeological Project and IIMAS, for supporting the research done by F. Buccellati at the AP Palace. This paper was originally presented at the CAA Conference at Siena, Italy on April 2, 2015; thanks goes to the Alexandria Archive Institute and IIMAS for supporting our participation. Sections 2, 3 and 5 were written by F. Buccellati, Sections 4 and 6 by E. Kansa while $1 \& 7$ were written jointly.

\section{References}

Abrams, E., 1994. How the Maya Built Their World: Energetics and Ancient Architecture. University of Texas Press, Austin, TX.

Buccellati, F., 2016. Three-Dimensional Volumetric Analysis in an Archaeological Context: The Palace of Tupkish at Urkesh and Its Representation. Vol. UMSX 15. Bibliotheca Mesopotamica. Undena Publications, Malibu, CA (forthcoming).

Buccellati, F., 2015. What might a field archaeologist want from an architectural 3D model?. In: Micale, M.G., Nadali, D. (Eds.), How Do We Want the Past to Be? On Methods and Instruments of Visualizing Ancient Reality. Gorgias, Piscataway, NJ, pp. 157-169.

Cresswell, R., 1990. 'A New Technology' Revisited. Technology and the humanities. Archaeol. Rev. Camb. 9 (1), 39-54.

Dobres, M.-A., 1999. Technology's Links and Chaînes. The Processual unfolding of technique and technician. In: Dobres, M.-A., Hoffman, C. (Eds.), The Social Dynamics of Technology: Practice, Politics, and World Views. Smithsonian Institution Press, Washington, pp. 124-146.

Geertz, C., 1973. The Interpretation of Cultures: Selected Essays. Basic Books, New York.

Lake, M., 2012. Open archaeology. World Archaeol. 44 (4), 471-478.

Kansa, E., 2012. Openness and archaeology's information ecosystem. World Archaeol. 44 (4), 498-520.

Kansa, E.C., Kansa, S.W., Goldstein, L., 2013. On ethics, sustainability, and open access in archaeology. SAA Archaeol. Rec. 13 (4), 15-22, Available at: 〈http://www. saa.org/Portals/0/SAA/Publications/thesaaarchrec/September2013.pdf).

Martinón-Torres, M., 2002. Chaîne Opératoire: the concept and its applications within the study of technology. Gallaecia 21, 29-43.

Parker, B., Cobb, P. 2012. "Kenan Tepe". In: Parker, B., Cobb, P. (Eds.) Kenan Tepe. Released: 2012-02-27. Open Context. 〈http://opencontext.org/projects/ 3DE4CD9C-259E-4C14-9B03-8B10454BA66E > DOI:http://dx.doi.org/10.6078/ M7H41PBJ ARK(Archive): 〈http://n2t.net/ark:/28722/k2xw47z1d〉.

Trigger, B., 1990. Monumental architecture: a thermodynamic explanation of symbolic behaviour. World Archaeol. 22 (2), 119-132.

Tuck, A., 2012. "Poggio Civitate from Italy". In: Tuck, A. (ed.) Murlo 〈http://open context.org/subjects/871B9EF8-BC68-4190-5F8A-00882C0040A4> ARK (Archive): 〈http://n2t.net/ark:/28722/k2gf0mz2d〉. 